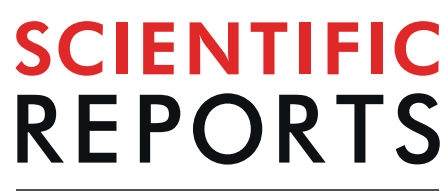

natureresearch

\title{
Removal of ammonium ion from aqueous solutions by using unmodified and $\mathrm{H}_{2} \mathrm{O}_{2}$-modified zeolitic waste
}

\author{
Danutè Vaičiukynienė $\mathbb{1}^{1,4^{*}}$, Agnè Mikelionienè $\dot{1}^{1,4}$, Arūnas Baltušnikas $\mathbb{1}^{2,4}$, Aras Kantautas ${ }^{3,4}$ \\ \& Algirdas Radzevičius ${ }^{1}$
}

In the petroleum industry during a catalytic cracking process, the used zeolitic catalyst becomes waste. This article investigated the sorption capacities of ammonium ions from aqueous solutions onto the previously mentioned zeolitic waste by batch experiments. Three types of zeolitic waste were used: unmodified zeolitic waste with two different particle size distributions and $\mathrm{H}_{2} \mathrm{O}_{2}$-modified zeolitic waste. Several techniques, including X-ray diffraction (XRD) analysis, Fourier transform infrared spectroscopy (FT-IR), Brunauer-Emmett-Teller (BET) multilayer adsorption theory measurements, and X-ray fluorescence analysis (XRF) were used to demonstrate experimentally that the zeolitic waste could be used as a sorbent for the water decontamination of $\mathrm{NH}_{4}{ }^{+}$ions. The morphology of zeolitic waste investigated by scanning electron microscopy (SEM) revealed particles with a spherical shape. The nitrogen adsorption-desorption isotherms showed an isotherm mixture of types I (pure microporous) and IV (mesoporous). This suggested that the investigated zeolitic materials were mesoporous $(4.84 \mathrm{~nm})$ and microporous $(0.852 \mathrm{~nm})$, as well as containing slit/cylindric pores, according to a quench solid density functional theory (OSDFT) adsorption branch model. Zeolitic waste from the oil industry showed good $\mathrm{NH}_{4}{ }^{+}$sorption properties (removal efficiency of $72 \%$ ), thus becoming a potential adsorbent to be used in the treatment of contaminated aqueous effluents polluted with ammonium ions. Simultaneous waste and water decontamination can be achieved, providing a new tool and enhanced capabilities for environmental remediation.

Ammonium $\left(\mathrm{NH}_{4}{ }^{+}\right)$is one of the common form of reactive nitrogen in wastewater ${ }^{1}$, and its contamination in fish causes serious health problems due to its high toxicity. The technologies for ammonia removal from wastewater are based on physicochemical and biochemical treatment methods ${ }^{2}$. One of these treatment methods is adsorption, which is a low-cost process. Different adsorbents, such as wheat straw biochars, pine sawdust or zeolites, can be effective in adsorbing ammonium in wastewater ${ }^{3-13}$. Yang et al. ${ }^{4}$ used some natural adsorbents such as pine sawdust and wheat straw biochars for the ammonium removal in wastewater. It was concluded that biochars can be efficient absorbents for $\mathrm{NH}_{4}^{+}$removal from aqueous solutions. Tian et al. ${ }^{5}$ synthesized a new sorbent using modified coal cinders and zeolite powders. This sorbent has been shown to be a good material for the removal of ammonia nitrogen. The removal efficiency of ammonia nitrogen was $67.3 \%$ and $71.3 \%$. The inflow concentrations of ammonia nitrogen were obtained under the experimental conditions where chemical oxygen demand under a water flow of $10 \mathrm{~L} / \mathrm{h}$. Yin et al. ${ }^{6}$ used NaCl-modified clinoptilolite as adsorbent for the nitrogen removal. Results in a current batch study provided that the maximum ammonium sorption capacity of clinoptilolite was in the range of 6.64 to $7.27 \mathrm{mg}$. N/g. The work reported by Sánchez-Hernández et al. ${ }^{7}$ evaluated the use of NaP1 zeolite for the removal of ammonium from aqueous solutions. The experiment of ammonium removal was conducted by the batch experiments. This zeolite was obtained from a hazardous Al-containing waste. These results indicate that the duration of the $\mathrm{NH}_{4}{ }^{+}$uptake on $\mathrm{NaP} 1$ was fast. Ammonium was removed within 15 minutes with high

${ }^{1}$ Faculty of Water and Land Management Agriculture Academy, Vytautas Magnus University, Studentu st. 11, Akademija, 53361, Lithuania. '2Laboratory of Materials Research and Testing, Lithuanian Energy Institute (LEI), Breslaujos st. 3, Kaunas, 44403, Lithuania. ${ }^{3}$ Faculty of Chemical Technology, Kaunas University of Technology, Radvilenu st. 19, Kaunas, 50254, Lithuania. ${ }^{4}$ These authors contributed equally: Danutè Vaičiukynienè, Agnè Mikelionienè, Arūnas Baltušnikas and Aras Kantautas. *email: danute.palubinskate@ktu.It 
sorption capacity $(37.9 \mathrm{mg} / \mathrm{g})$. Huo et $\mathrm{al} .{ }^{8}$ reported that a salt and a thermally modified clinoptilolite had the potential effectively to remove ammonia. This modified zeolite had rapid adsorption and slow balance characteristics. An entropy effect is very important in the adsorption process. Xue et al. ${ }^{9}$ examined different types of zeolites for ammonia removal in high ammonia water. According to this experimental results it could be concluded that mordenite is suitable to remove ammonia from water.

Several studies have reported on the adsorption of ammonium ions by natural or synthetic zeolitic material adsorbents as well ${ }^{10-13}$. Zeolite - aluminosilicate hydrate minerals with a porous, three-dimensional crystal structure are considered an excellent ion-exchange material because of their high selectivity for $\mathrm{NH}_{4}{ }^{+}$due to their microstructure ${ }^{3}$. An adsorbent of natural zeolites possesses a polar surface and is therefore able to attract ammonium ions quickly and effectively ${ }^{2}$. The removal of ammonia from water was carried out by using natural and synthetic zeolites. In this research three types of natural zeolites (clinoptilolite, mordenite and ferrierite), and synthetic zeolite A were used. The different forms of zeolites such as sodium, potassium and calcium forms were investigated ${ }^{10}$. It were concluded that natural zeolites show high selectivity for ammonium ions with respect to other monovalent ions despite the much higher theoretical exchange capacity of zeolite A. In the study ${ }^{11}$, the clinoptilolite was fused with sodium hydroxide prior to a hydrothermal reaction, and it was transformed to a modified zeolite $\mathrm{Na}-\mathrm{Y}$. The results were acceptable, showing that modified zeolite $\mathrm{Na}-\mathrm{Y}$ exhibited a much higher uptake capacity compared with that of clinoptilolite. At an initial concentration of $250 \mathrm{mg} / \mathrm{L} \mathrm{NH}_{4}^{+}$, the ammonium ion uptake value of sample 2 was $19.29 \mathrm{mg} / \mathrm{g} \mathrm{NH}_{4}{ }^{+}$adsorbed, while that for sample 1 was only $10.49 \mathrm{mg} / \mathrm{g}^{1}$ $\mathrm{NH}_{4}{ }^{+}$adsorbed. Markou et al. ${ }^{12}$ investigated zeolites which were synthesized from coal fly ash in sodium form and in potassium form as well. These zeolitic materials were used as sorbents for ammonium removal. According to this study the maximum sorption capacities were $109 \pm 4 \mathrm{mg} / \mathrm{g} \mathrm{NH}_{4}$ and $33 \pm 1 \mathrm{mg} / \mathrm{g} \mathrm{NH}_{4}$ for sodium form zeolite and potassium form zeolite, respectively. Wu et al. ${ }^{14}$ investigated novel granular adsorbents produced with zeolite powders and an Al-Mn binary oxide via a compression method for removing ammonium from wastewater. Kinetic adsorption results indicated a fast adsorption rate for $\mathrm{NH}_{3}-\mathrm{N}$, and the maximum adsorption capacity of $\mathrm{NH}_{3}-\mathrm{N}$ was $12.9 \mathrm{mg} / \mathrm{g}$ via the Langmuir model.

There is some research related to improving aquaculture water quality using of natural or synthetic zeolites. Ammonia removal was conducted using an aquaponics-zeolite system ${ }^{13}$. Green mustards were used as aquaponic plants, and natural zeolites were modified using sodium chloride $(0-5 \%)$. The aquaponic and zeolite adsorption method had a significant effect on a fish pond. Bergero et al. ${ }^{15}$ tested ammonia removal from aquaculture water in recirculating systems by using as adsorbent different types of zeolites under laboratory conditions. Natural zeolites such as phillipsite and clinoptilolite tuffs were beneficial in ammonia removal. Another type of natural zeolitic material (chabazitic tuff with a lower amount of zeolitic material (50\%)) _ had a lower cation exchange capacity for ammonia. It was concluded that, a lower temperature did not effected significantly the ion exchange capacity in any of the investigated zeolites. The results of this type fish farming water treatment would benefit in the design of a new nutrient purification tool. This water treatment method is close related with the sustainable management of aquaculture.

There are many articles on the removal of ammonium ions using different natural and synthetic sorbents, but information related to $\mathrm{NH}_{4}^{+}$sorption using zeolitic waste has not been found. In this study, the zeolitic waste from fluid catalytic cracking (FCC) catalysts was used as adsorbents for ammonium ions. Previous investigations have shown that this waste exhibits good removal properties for chromium removal ${ }^{16}$, encapsulates heavy metals ${ }^{17}$, and is suitable for recycling phosphogypsum (it adsorbs harmful admixtures) ${ }^{18}$.

In spite of existing reports on $\mathrm{NH}_{4}{ }^{+}$removal using natural or synthetic zeolites, the present study suggests the use of zeolitic waste as a sorbent material. Thus, in this way, it will be possible to reuse zeolitic waste and save natural resources when natural zeolites are used as sorbents. Furthermore, using a zeolitic waste sorbent for $\mathrm{NH}_{4}{ }^{+}$ removal would be more economical than previous applications where natural or synthetic zeolite were used.

The aim of this study is to determine the $\mathrm{NH}_{4}{ }^{+}$sorption removal efficiency of three different types of zeolitic waste from the oil industry. Two types were unmodified zeolitic waste with two different particle size distributions, and the third type was a $\mathrm{H}_{2} \mathrm{O}_{2}$-modified zeolitic waste.

\section{Experimental}

Experimental techniques. The chemical composition of zeolitic waste was determined by X-ray fluorescence spectrometry (XRF) on a Bruker X-ray S8 Tiger WD using a rhodium (Rh) tube, an anode voltage $U_{a}$ up to $60 \mathrm{kV}$, and an electric current $I$ up to $130 \mathrm{~mA}$. The pressed samples were measured in a helium atmosphere. Measurements were performed using a SPECTRA Plus QUANT EXPRESS method ${ }^{19}$.

$\mathrm{X}$-ray diffraction analysis (XRD) of the materials was performed using a D8 Advance diffractometer (Bruker AXS) operating at a tube voltage of $40 \mathrm{kV}$ and a tube current of $40 \mathrm{~mA}$. The X-ray beam was filtered with a $\mathrm{Ni}$ $0.02-\mathrm{mm}$ filter to select a $\mathrm{CuK} \alpha$ wavelength. The specimens were scanned over a $2 \theta$ range from $3^{\circ}$ to $70^{\circ}$ at a scanning speed of $6^{\circ} \mathrm{min}^{-1}$ using a coupled two theta/theta scan type $\mathrm{e}^{20}$.

A laser particle size analyzer (CILAS 1090 LD) determined the particle size distribution and the specific surface area of the investigated materials in intervals from 0.04 to $500 \mu \mathrm{m}$. The distribution of solid particles in the air stream was $12-15$ wt.\%. Compressed air (2500 mbar) was used as a dispersing phase. The measuring time was $15 \mathrm{~s}^{21}$.

The microstructures of the three types of zeolitic waste were studied by scanning electron microscopy. A high-resolution scanning electron microscope (ZEISS EVO MA10) was used for the research ${ }^{22}$.

The $\mathrm{pH}$ measurements of water suspensions were conducted by using a WTW pH 320 pH-meter.

Fourier transform infrared (FT-IR) spectrometry was conducted with a Perkin Elmer FT-IR System spectrometer. One milligram of the substance was mixed with $200 \mathrm{mg}$ of $\mathrm{KBr}$ and compressed in a forming press under vacuum for the IR analysis ${ }^{23}$. 


\begin{tabular}{|l|l|l|l|}
\hline Element & Zeo waste 1 & Zeo waste 2 & Zeo waste 3 \\
\hline Oxygen & 54.51 & 54.22 & 52.37 \\
\hline Carbon & 3.31 & 1.25 & 3.34 \\
\hline Aluminium & 23.00 & 24.92 & 24.25 \\
\hline Silicon & 16.18 & 15.77 & 16.34 \\
\hline Magnesium & 0.44 & 0.91 & 0.82 \\
\hline Sulfur & 0.15 & - & 0.19 \\
\hline Calcium & - & - & 0.47 \\
\hline Sodium & 0.07 & 0.02 & 0.09 \\
\hline Iron & 0.81 & 1.17 & 0.69 \\
\hline Titanium & 0.39 & 0.65 & 0.26 \\
\hline Lanthanum & 1.15 & 1.09 & 1.18 \\
\hline
\end{tabular}

Table 1. Chemical composition of the zeolitic waste (XRF), wt. \%.

The textural parameters of the samples were determined by nitrogen adsorption-desorption isotherms at $-196^{\circ} \mathrm{C}(77 \mathrm{~K})$ using a Quantachrome Autosorb-iQ-KR/MP automated gas sorption analyzer. Prior to the analysis, the powder samples were outgassed under vacuum at $105^{\circ} \mathrm{C}$ for $3 \mathrm{~h}$. The specific surface area was calculated by using the BET (Brunauer-Emmett-Teller) equation. The pore size distribution was determined by applying the density functional theory (DFT). The total pore volume was measured from the adsorption isotherm by the uptake of nitrogen at a relative pressure of $\mathrm{p} / \mathrm{p}_{0}=0.99$. All calculations were performed by an ASiQwin (Version 2.0) program developed by Quantachrome Instrument ${ }^{24}$.

The evaluation of the $\mathrm{NH}_{4}{ }^{+}$concentration was evaluated according to the Nessler method, and the ammonium $\left(\mathrm{NH}_{4}^{+}\right)$concentration was measured by a UV-VIS spectrophotometer (SPECORD PLUS). An ammonium chloride $\left(\mathrm{NH}_{4} \mathrm{Cl}\right)$ salt was used to make the $\mathrm{NH}_{4}^{+}$solutions.

The ion exchange of $\mathrm{NH}_{4}{ }^{+}$ions on the zeolite was carried out using a batch method. The batch experiments were conducted with $2 \mathrm{~g}$ of adsorbent in $200 \mathrm{ml}$ of solutions with $1 \mathrm{mg} / \mathrm{L} \mathrm{NH}_{4}{ }^{+}$and $10 \mathrm{mg} / \mathrm{L} \mathrm{NH}_{4}{ }^{+}$. Then, all samples were left at $20^{\circ} \mathrm{C}$ under static conditions for $1 \mathrm{~h}, 12 \mathrm{~h}, 24 \mathrm{~h}, 48 \mathrm{~h}$ and $72 \mathrm{~h}$. Ammonium standard solution $\left(1000 \mathrm{mg} / \mathrm{L} \mathrm{NH}_{4}{ }^{+}\right)$and deionized water were used for the preparation of the initial ammonium solutions. The $\mathrm{pH}$ of the solutions was also evaluated.

The removal efficiency (\%) and the amount of exchanged $\mathrm{NH}_{4}{ }^{+}$ion $\left(q_{e}\right)$ by the zeolite were evaluated using Eqs. (1) and (2), respectively ${ }^{25}$ :

$$
\begin{gathered}
\text { Removal efficiency }(\%)=\frac{\left(C_{0}-C_{e}\right)}{C_{0}} \cdot 100 \% ; \\
q_{e}=\frac{\left(C_{0}-C_{e}\right) V}{m} .
\end{gathered}
$$

where $q_{e}$ is the amount of exchanged ammonium ions $(\mathrm{mg} / \mathrm{g}), C_{0}$ and $C_{e}$ are the initial and equilibrium concentrations of ammonium in solution $(\mathrm{mg} / \mathrm{L})$, respectively, $V$ is the solution volume $(\mathrm{L})$, and $m$ is the adsorbent weight (g).

In solution, the experiment for the amount of $\mathrm{NH}_{4}{ }^{+}$was repeated at least three times. The mean value of the triple analysis was used to calculate the amount of $\mathrm{NH}_{4}{ }^{+}$in solution, and the limit of error for the samples was lower than $5 \%$.

The point of zero charge, pHpzc, of the investigated zeolitic waste was evaluated according to Nasiruddin et $a l .{ }^{26}$. For this purpose, a pH drift method was used. Sodium chloride $(0.01 \mathrm{M})$ was used as a background electrolyte. Initial solutions with $\mathrm{pH}$ values in a range from 2 to 9 were prepared by adding small amounts of $0.5 \mathrm{M} \mathrm{HCl}$ or $0.5 \mathrm{M} \mathrm{NaOH}$ solutions. Then, in each simulated solution $(20 \mathrm{ml}), 0.5 \mathrm{~g}$ of zeolitic material samples were added, and the samples were left to settle for $24 \mathrm{~h}$ at room temperature. The final $\mathrm{pH}$ of each solution was measured. The $\mathrm{pHpzc}$ of zeolitic materials was evaluated; if the initial $\mathrm{pH}$ of the solution was equal to the final $\mathrm{pH}$ of the solution, then that was considered the $\mathrm{pHpzc}^{27}$, and the charge on the surface was zero.

\section{Materials}

Zeolitic catalysts are very important in the petroleum refining industry as fluid catalytic cracking (FCC) units. In this study, the waste FCC catalyst was used as zeolitic waste. After some time during processing, zeolite can be polluted with oil products such as coke, sulfur, vanadium and nickel. After that, it became unsuitable for use in oil technology. The quantity of this waste inevitably rises due to a rapidly expanding oil industry. The composition of these catalysts depends on the manufacturer and on the process that is going to be used.

Due to cation exchange capacity and molecular network properties, zeolites are widely used as adsorbents in separation and purification processes. Zeolitic waste was used for the sorption of ammonium ions. The general chemical composition of zeolitic waste was measured according to XRF and is presented in Table 1. In all zeolitic waste, silicon and aluminum prevail with small amounts of carbon, lanthanum, magnesium and titanium.

All chemicals, such as ammonium chloride $\left(\mathrm{NH}_{4} \mathrm{Cl}\right)$, hydrogen peroxide $\left(\mathrm{H}_{2} \mathrm{O}_{2}\right)$ and sodium hydroxide $(\mathrm{NaOH})$ were analytical grade. 


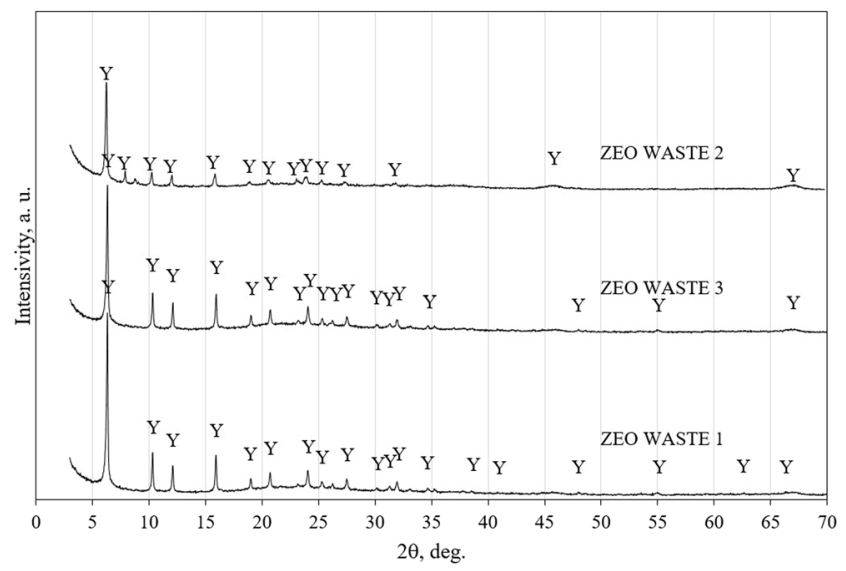

Figure 1. The X-ray diffraction patterns of zeolitic waste. Note: $\mathrm{Y}$ is zeolite $\mathrm{Al}_{60.352} \cdot \mathrm{Si}_{139} \cdot \mathrm{O}_{371 \cdot 52} \cdot \mathrm{H}_{5.984}(73-2313)$.

\section{Results and Discussion}

The modification of zeolitic waste by using hydrogen peroxide solution. Zeolites are often modified to improve their sorption capacity. There are various zeolite modification and activation methods. One method for zeolitic waste modification is to use hydrogen peroxide $\left(\mathrm{H}_{2} \mathrm{O}_{2}\right) . \mathrm{H}_{2} \mathrm{O}_{2}$ is an active oxidizer and is commonly used to transform, immobilize or remove carbonaceous impurities from zeolites. Canli et al. ${ }^{28}$ concluded that zeolite activation with $\mathrm{H}_{2} \mathrm{O}_{2}$ can improve the zeolite sorption capacity. The oxidation process of $\mathrm{H}_{2} \mathrm{O}_{2}$ has also been investigated for the regeneration of sorption properties of hydrophobic zeolites ${ }^{29,30}$. According to Singh et al. and Koryabkina et al., one of the advantages of using hydrogen peroxide in regenerative processes is that the hydrogen peroxide decomposition products are oxygen and water, which are environmentally friendly.

Thus, the last type of zeolitic material was $\mathrm{H}_{2} \mathrm{O}_{2}$-modified zeolitic waste (Zeo waste 2). The zeolitic waste was added to a $15 \% \mathrm{H}_{2} \mathrm{O}_{2}$ aqueous solution and left for $24 \mathrm{~h}$ at ambient temperature. After that solution was separated from zeolitic waste by filtration, it was dried at $100^{\circ} \mathrm{C}$ for $24 \mathrm{~h}$. The chemical composition of Zeo waste 2 is shown in Table 1. According to the chemical analysis of this material, the amount of carbon (technically coke) significantly decreased from $3.31 \%$ in the unmodified zeolitic waste to $1.25 \%$ in the $\mathrm{H}_{2} \mathrm{O}_{2}$-treated zeolitic waste. Furthermore, sulfur was not detected at all. Therefore, by treating the waste with $\mathrm{H}_{2} \mathrm{O}_{2}$ solution during oxidation reactions, it can eliminate oil product pollutants such as coke and sulfur as well.

The mineral composition of the three types of zeolitic waste was evaluated by using XRD analysis (Fig. 1). This analysis showed that in all materials, similar minerals prevail. The mineral composition consisted of zeolite $\mathrm{Y} \mathrm{Al}_{60 \cdot 352} \cdot \mathrm{Si}_{139} \cdot \mathrm{O}_{371 \cdot 52} \cdot \mathrm{H}_{5 \cdot 984}$. The main diffraction peaks belonged to this mineral and had main interplanar distances (d) of $1.399,0.857,0.731,0.556,0.429$, and $0.370 \mathrm{~nm}$.

Therefore, after the modification of zeolitic waste with a hydrogen peroxide solution, the mineral composition of the zeolitic waste did not change, but the amount of carbon significantly decreased, and sulfur was not detected in this material (Table 1).

Particle size distribution and morphology of zeolitic waste. The particle size of zeolitic byproduct powder is very useful for predicting the main characteristics of ammonium sorption. The effect of particle size with the three different zeolitic waste products was evaluated. It is known that zeolitic powder size has a large influence on the sorption rate and maximum sorption capacity. Therefore, the ammonium sorption increased with decreasing zeolite particle size ${ }^{31,32}$.

Figure 2 demonstrates the particle size distribution of zeolitic waste powders and the microstructure of these powders. All three types of zeolitic waste powder had similar narrow particle size distributions. Zeo waste 1 had a mean particle diameter of $97.95 \mu \mathrm{m}$. Zeo waste 2 powder was similar to Zeo waste 1 with a value of $78.39 \mu \mathrm{m}$, and Zeo waste 3 had particles that were more than four times finer (mean diameter of $23.26 \mu \mathrm{m}$ ) compared with the powder from Zeo waste 1 . In a catalytic cracker, a zeolite catalyst is used. In a closed system, the circulation of this catalyst occurs. After some time, the zeolitic catalyst becomes finer due to mechanical action, contact with hydrocarbons, water vapor, and the combustion process. Then, the zeolitic dust is separated by separators.

Table 2 demonstrates the particle size analysis characteristics of the three different samples. The particle size analysis showed that the zeolitic waste powder had a wide particle size distribution ranging from $177.81 \mu \mathrm{m}$ to $19.80 \mu \mathrm{m}$ and from $140.04 \mu \mathrm{m}$ to $31.46 \mu \mathrm{m}$ for Zeo waste 1 and Zeo waste 2, respectively. The narrower particle size distribution, ranging from $39.00 \mu \mathrm{m}$ to $10.39 \mu \mathrm{m}$, was for Zeo waste 3 .

The particle size distributions measured are in agreement with the SEM micrographs (Fig. 2b). In all three cases, the particles of the powders were spherical in shap $\mathrm{e}^{33}$. Additionally, it could be observed that finer particles prevail in Zeo waste 3 compared with those in Zeo waste 1 and Zeo waste 2, which have similar sizes.

The textural properties of zeolitic waste. The surface area and pore structure are important parameters for the ammonium sorption capacity of zeolitic waste. According to these parameters, it is possible to predict the main characteristic of ammonium sorption. 

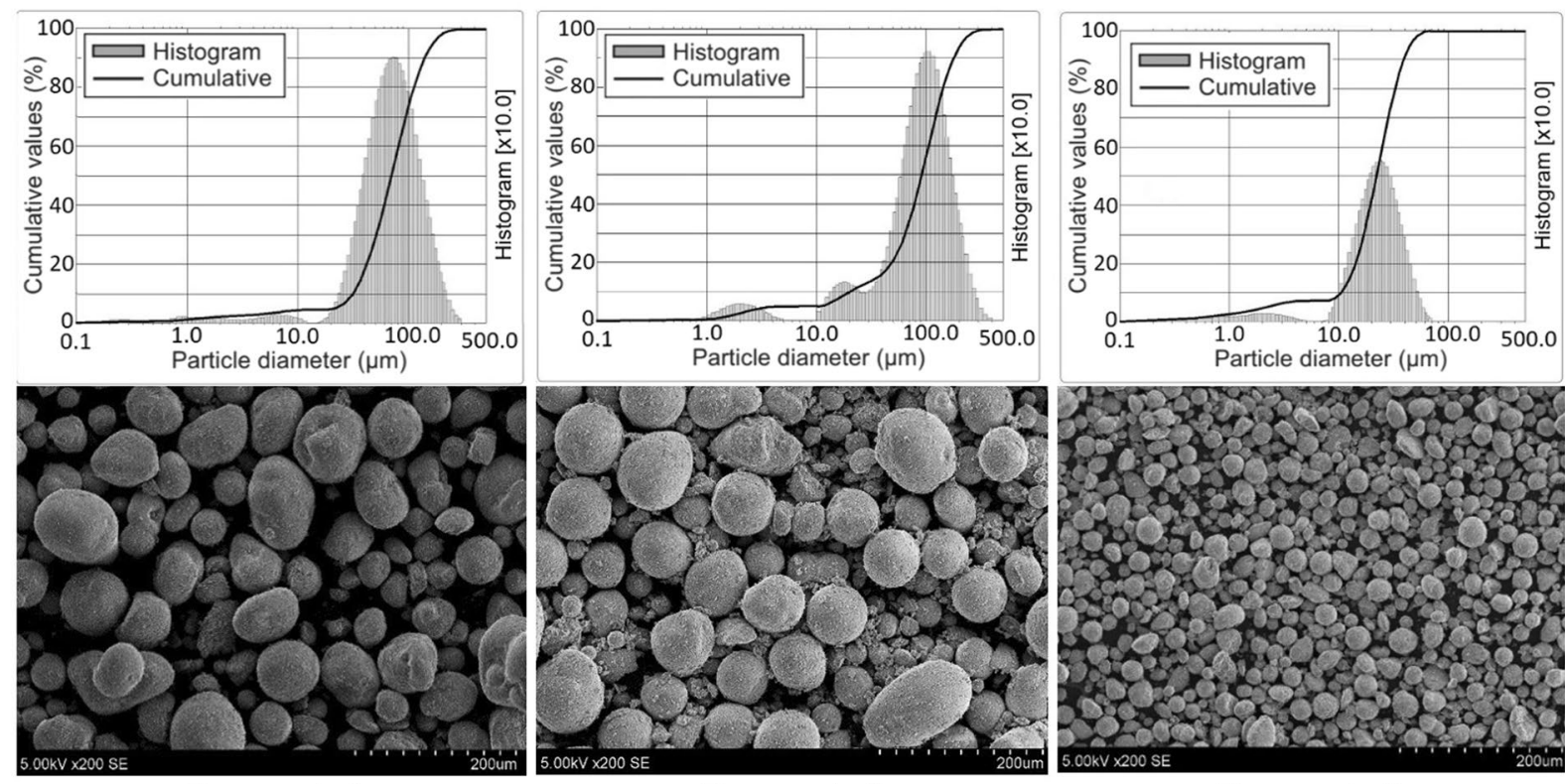

Zeo waste 1

Zeo waste 2

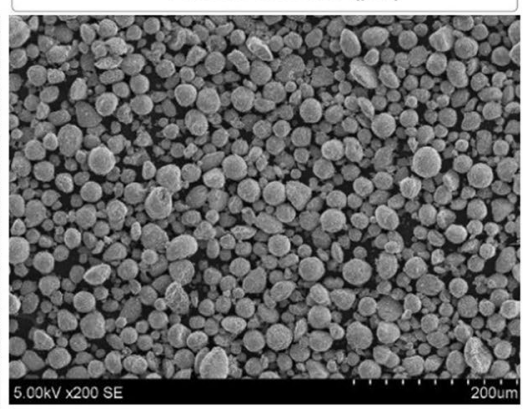

Zeo waste 3

Figure 2. Scanning electron micrographs and particle size distribution of zeolitic waste powder.

\begin{tabular}{|l|l|l|l|l|}
\hline $\begin{array}{l}\text { Zeolitic } \\
\text { waste }\end{array}$ & $\mathbf{d 9 0 ,} \boldsymbol{\mu m}$ & $\mathbf{d 5 0 ,} \boldsymbol{\mu m}$ & $\mathbf{d 1 0 ,} \boldsymbol{\mu m}$ & Mean diameter, $\boldsymbol{\mu m}$ \\
\hline Zeo waste 1 & 177.81 & 90.91 & 19.80 & 97.95 \\
\hline Zeo waste 2 & 140.04 & 69.67 & 31.46 & 78.39 \\
\hline Zeo waste 3 & 39.00 & 22.02 & 10.39 & 23.26 \\
\hline
\end{tabular}

Table 2. Characteristics of the powder mixtures obtained from particle size distributions.

\begin{tabular}{|l|l|l|l|l|}
\hline & & \multicolumn{3}{|l|}{ Pore structure } \\
\cline { 3 - 5 } Material & $\mathbf{S}_{\mathrm{BET}}, \mathbf{~}^{2} / \mathbf{g}$ & $\mathbf{S}_{\text {Pore }}, \mathbf{~}^{2} / \mathbf{g}$ & $\begin{array}{l}\text { Average pore } \\
\mathbf{s i z e}, \mathbf{~} \mathbf{m}\end{array}$ & $\begin{array}{l}\text { Pore volume, } \\
\mathbf{c m}^{3} / \mathbf{g}\end{array}$ \\
\hline Zeo waste 1 & 137.69 & 138.43 & 0.852 & 0.187 \\
\hline Zeo waste 2 & 137.39 & 143.70 & 0.852 & 0.173 \\
\hline Zeo waste 3 & 138.89 & 130.08 & 0.852 & 0.169 \\
\hline
\end{tabular}

Table 3. $\mathrm{N}_{2}$ adsorption-desorption results of zeolitic waste.

The surface area and pore structure of the three types of zeolitic waste were investigated by analyzing nitrogen adsorption-desorption isotherms. The BET specific surface area of the zeolitic particles, the specific surface area of the pores, the average pore size and the pore volume are presented in Table 3.

The main textural results of the zeolitic waste show that there are similar values in surface area. The

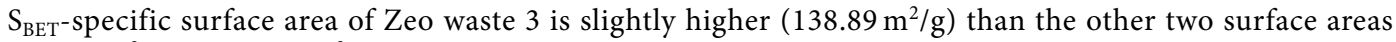
$\left(137.69 \mathrm{~m}^{2} / \mathrm{g}\right.$ and $\left.137.39 \mathrm{~m}^{2} / \mathrm{g}\right)$ of Zeo waste 1 and Zeo waste 2 , respectively.

After modifying Zeo waste 1 with a hydrogen peroxide solution, $\mathrm{S}_{\mathrm{BET}}$ remained almost unchanged, but $\mathrm{S}_{\text {Pore }}$ slightly increased from $138.43 \mathrm{~m}^{2} / \mathrm{g}$ to $143.70 \mathrm{~m}^{2} / \mathrm{g}$ for Zeo waste 1 and Zeo waste 2, respectively (Table 3). This could be related to the $\mathrm{H}_{2} \mathrm{O}_{2}$ solution reacting with the zeolite, which resulted in the removal of carbonaceous impurities and sulfur.

According to the International Union of Pure and Applied Chemistry (IUPAC) classification ${ }^{34}$, the obtained isotherms of Zeo waste 1, Zeo waste 2 and Zeo waste 3 (Fig. 3) could be attributed to type I and IV isotherms. A type I isotherm is chosen because of an increasing ratio of $P / P_{0}$ from 0 to 0.4 ; thus, the process proceeds according to the type I isotherm, where micropores are predominant. A type IV isotherm occurs when the ratio of $P / P_{0}$ varies from 0.4 to 1 , and according to the type IV isotherm, a mesoporous structure predominates and forms a hysteresis loop. Therefore, the nitrogen isotherms of the samples were a combination of type I at lower relative pressures $\left(P / P_{0}\right)$ and type IV at high values of $P / P_{0}$, suggesting the existence of both micropores and mesopores in the sample.

S. Brunauer, P.H. Emmett and E. Teller in ${ }^{35}$ derived an isotherm labeled as shown in Eq. (3): 


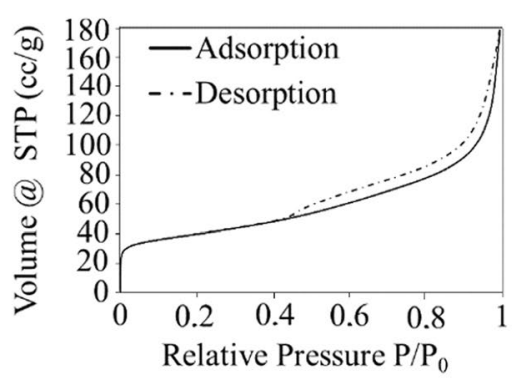

Zeo waste 1

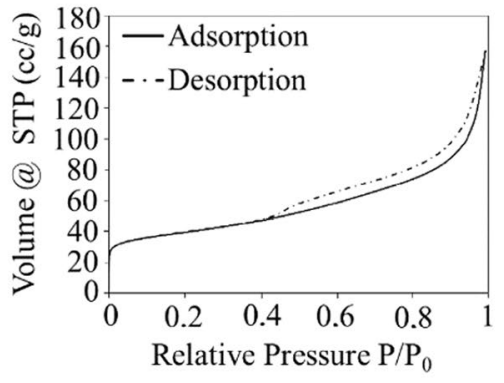

Zeo waste 2

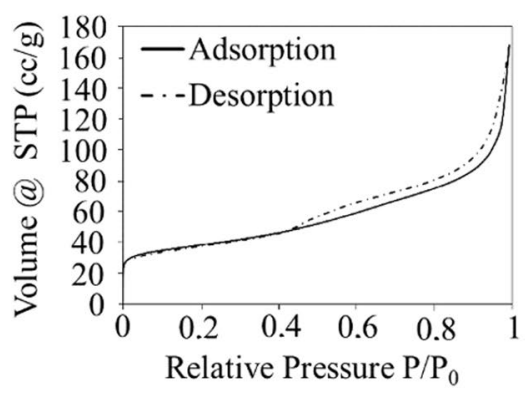

Zeo waste 3

Figure 3. Adsorbption/desorbtion isotherms of $\mathrm{N}_{2}$.

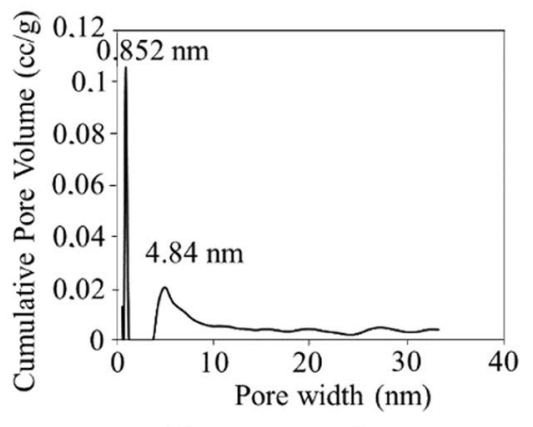

Zeo waste 1

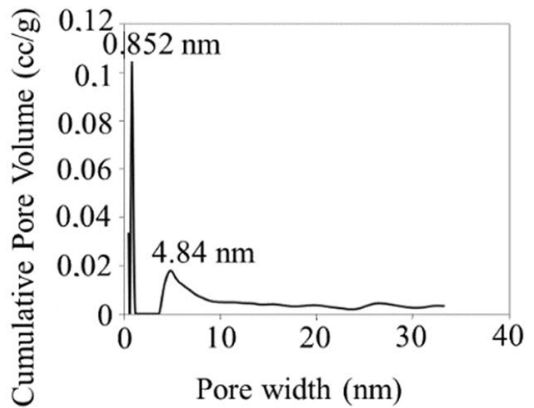

Zeo waste 2

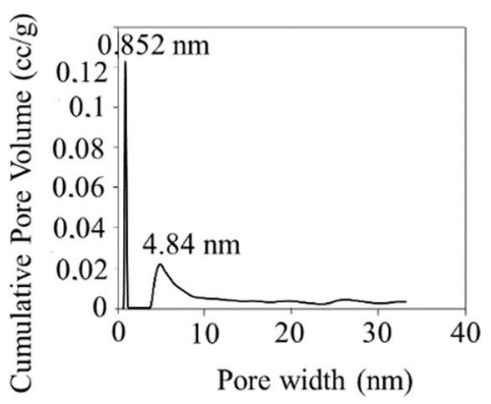

Zeo waste 3

Figure 4. The distribution of the pore structure (PSD DFT slit-cylindric pores model).

$$
v=\frac{v_{m} c P}{\left(P_{0}-P\right)\left[1+(c-1)\left(P / P_{0}\right)\right]} ;
$$

where $v$ is the volume of adsorbate at some $P / P_{0}, v_{m}$ is the volume of gas adsorbed when the entire adsorbent surface is covered with a complete unimolecular layer, $P$ is the gas pressure, $P_{0}$ is the saturation pressure of the gas, and $c$ is a constant associated with the energy of adsorption.

The above results are confirmed by calculations using the DFT method. In these materials, micropores with a size of $0.852 \mathrm{~nm}$ (diameter) and mesopores with a size of $4.84 \mathrm{~nm}$ dominate by using a "slit/cylindric pore, QSDFT adsorption branch" model (Fig. 4). If the "slit pore, QSDFT equilibrium model" is used, mesopores with a size of $3.39 \mathrm{~nm}$ dominate. By using a Type I model, the mismatches between the experimental and model curves are $0.537 \%, 0.641 \%$ and $0.652 \%$, and for the second model, they are $0.982,1.133$ and $1.097 \%$, for the Zeo waste 2, Zeo waste 3 and Zeo waste 1 samples, respectively. Therefore, it was interpreted that a "slit/cylinder" model was more fitting to describe the measurement curve. However, if it were based on classical BJH methodology, then according to $\mathrm{BJH}$, the analyzed waste would contain $3.707 \mathrm{~nm}$ mesopores, which would then be in closer relation to the "slit pore, QSDFT equilibrium model" calculations of mesopores. Unfortunately, the size of micropores cannot be obtained according to BJH methodology. Nevertheless, with the knowledge that BJH methodology always calculates smaller pore sizes than QSDFT, we state that the "slit/cylinder pores, QSDFT adsorption branch model" best describes the analyzed zeolitic waste.

Ammonium sorption capacity of zeolitic waste. The ammonium removal capacities of zeolitic waste with different particle sizes were investigated. Adsorption processes in zeolitic materials were performed under two different ammonium concentrations: $1 \mathrm{mg} / \mathrm{L}$ and $10 \mathrm{mg} / \mathrm{L}$ initial solutions. For the removal of ammonium ions from water solutions, three types of zeolitic waste were chosen.

According to the fundamentals of an ion-exchange reaction ${ }^{36}$ with zeolitic waste, a chemical process involving valence forces is described through the sharing or exchange of electrons between negatively charged zeolite sites and ammonium cations as expressed by using the following equation:

$$
\text { Zeolite }-\mathrm{H}_{3} \mathrm{O}^{+}+n \mathrm{NH}_{4}^{+} \leftrightarrow \text { Zeolite }-n \mathrm{NH}_{4}^{+}+\mathrm{H}_{3} \mathrm{O}^{+}
$$

where $\mathrm{H}$ represents exchangeable ions in zeolite and $n$ is the number of electric charges.

First, the required time for the sorption equilibrium time was determined. After $1 \mathrm{~h}$ of sorption duration, significant ammonium ion sorption was performed (Figs. 5 and 6). During this time, the removal efficiency of $\mathrm{NH}_{4}^{+}$ ions for Zeo waste 1 was $33 \%$, Zeo waste 3 was $47 \%$ and the highest removal efficiency of $56 \%$ was reached for Zeo waste 2 when the initial $\mathrm{NH}_{4}^{+}$ion concentration was $1 \mathrm{mg} / \mathrm{L}$ (Fig. 5a). Equilibrium times were reached in $48 \mathrm{~h}$ 


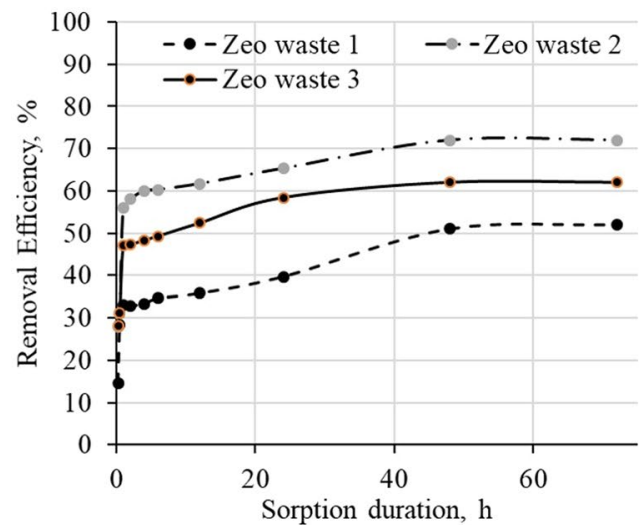

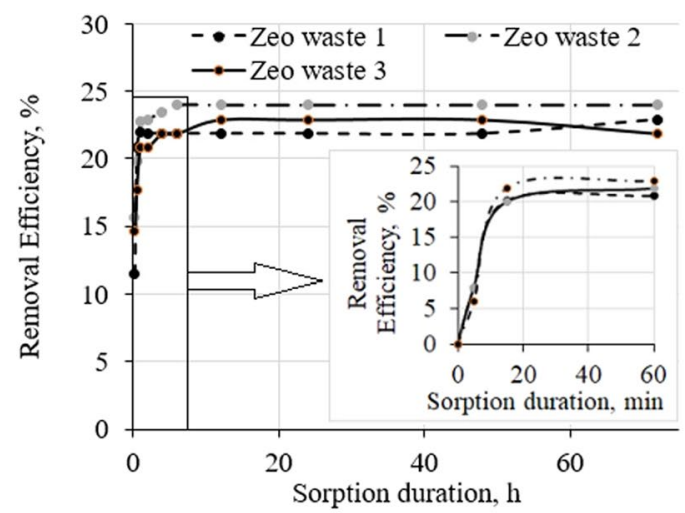

b

Figure 5. Removal efficiency of $\mathrm{NH}_{4}{ }^{+}$ion from aqueous solutions by batch experiments. Initial concentrations: $a-C_{0}=1 \mathrm{mg} / \mathrm{L}$ and $b-C_{0}=10 \mathrm{mg} / \mathrm{L}$.

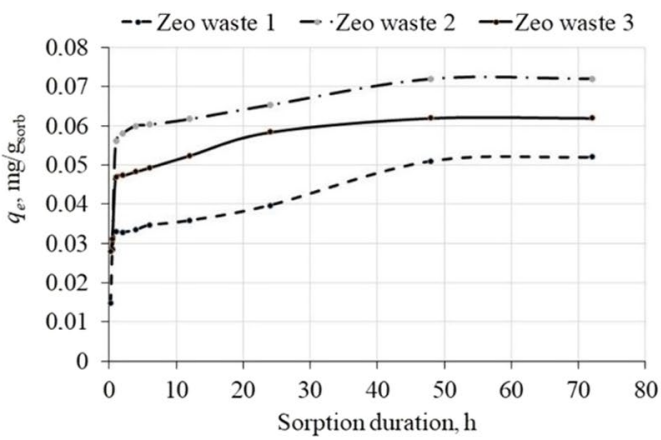

a

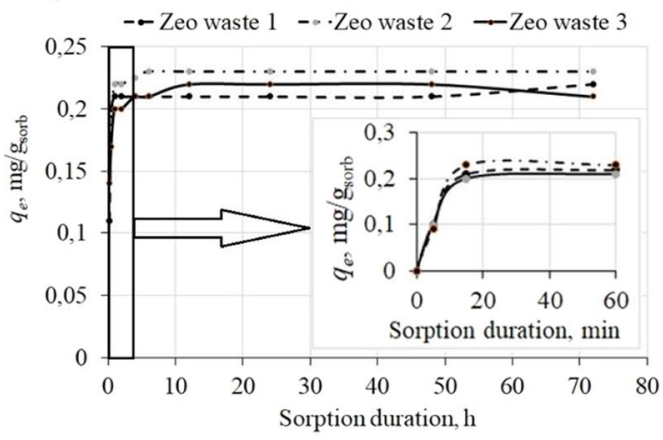

b

Figure 6. Amounts of exchanged $\mathrm{NH}_{4}{ }^{+}$ion $q_{e}, \mathrm{mg} / \mathrm{g}$ from aqueous solutions by batch experiments. Initial concentrations: $a-C_{0}=1 \mathrm{mg} / \mathrm{L}$ and $b-C_{0}=10 \mathrm{mg} / \mathrm{L}$.

for all three types of zeolitic waste. After a longer contact time, the removal efficiency gradually increased, and a similar range of zeolitic waste removal efficiency was determined: Zeo waste $2(72 \%)>$ Zeo waste $3(62 \%)>$ Zeo waste $1(52 \%)$. It can be stated that equilibrium times became shorter with an increased initial concentration of $\mathrm{NH}_{4}+\left(C_{0}=10 \mathrm{mg} / \mathrm{L}\right)$ in the purified solutions (Fig. $5 \mathrm{~b}$ ). Equilibrium times were reached after $15 \mathrm{~min}$ in these cases. Removal efficiency reached approximately $23 \%$ for all three types of zeolitic waste, and significant differences between the used types of zeolitic waste were not detected. Franus et al. ${ }^{37}$ published similar results related to experiments in ammonium ion removal. They stated that the amount of $\mathrm{NH}_{4}{ }^{+}$ions removed from aqueous solutions increased with increasing concentrations of $\mathrm{NH}_{4}{ }^{+}$ions in the purified solution.

The ion exchange capacity of Zeo waste 2 was $0.072 \mathrm{mg} / \mathrm{g}$; for Zeo waste 3, it was $0.062 \mathrm{mg} / \mathrm{g}$ and $0.052 \mathrm{mg} / \mathrm{g}$ for Zeo waste 1 when the initial $\mathrm{NH}_{4}{ }^{+}$ion concentration was $1 \mathrm{mg} / \mathrm{L}$. When the initial concentration increased to $10 \mathrm{mg} / \mathrm{L}$, higher values (approximately $0.23 \mathrm{mg} / \mathrm{g}$ ) of exchanged $\mathrm{NH}_{4}{ }^{+}$ions were reached, and the amount of exchanged $\mathrm{NH}_{4}{ }^{+}$ions was similar for all zeolitic waste.

Based on the experimental results, it can be stated that zeolitic waste with finer particles (Zeo waste 3) has better removal efficiency compared with that of coarser zeolitic waste particles (Zeo waste 1), especially when the initial $\mathrm{NH}_{4}{ }^{+}$ion concentration was lower $(1 \mathrm{mg} / \mathrm{L})$. Therefore, the ammonium sorption increased with decreasing particle size of the zeolites ${ }^{32}$. This could be related to the ammonium cations having a much easier exchange with smaller zeolite particles that are in the aqueous solution. The BET surface area is calculated with the entire surface area, such as the surface of the pores and the external surface of the material, and is calculated by the adsorption of nitrogen gas on the surface of the materials. The BET surface area is generally higher than the total surface area, which depends on the particle size. Therefore, the BET surface area is not directly dependent on the particle size of zeolites, which is almost the same (Table 3). The best results of ammonium sorption were determined for Zeo waste 2 , which was modified with $\mathrm{H}_{2} \mathrm{O}_{2}$. The removal efficiency was $72 \%$ after equilibrium was reached.

The initial ammonium concentration is an important aspect in the sorption process of ammonium on zeolite. The adsorption efficiencies are varied at a lower initial concentration $\left(C_{0}=1 \mathrm{mg} / \mathrm{L}\right)$ of ammonia but are almost the same at higher concentrations $\left(C_{0}=10 \mathrm{mg} / \mathrm{L}\right)$ of ammonia (Figs. 5 and 6$)$. This could be explained by the porous microstructure of zeolites. By increasing the initial ammonium concentration, the mass transfer driving force and the rate at which ammonium ions pass to the surface of the zeolite also increased. Therefore, the ammonium ions 


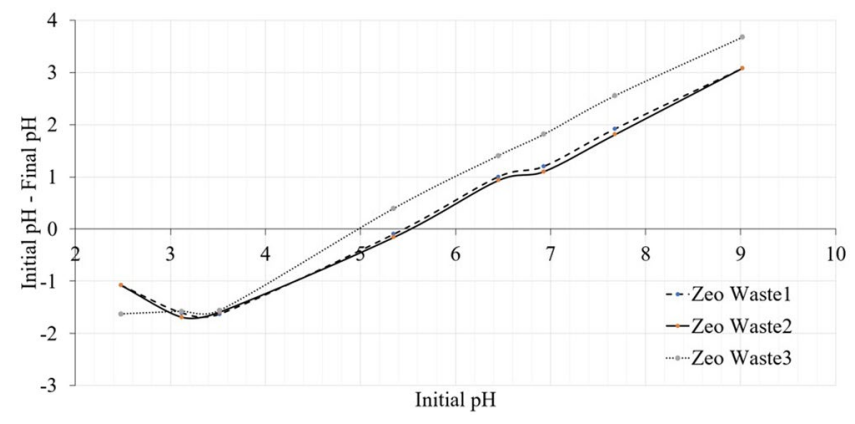

Figure 7. Determination of zero point charge of zeolitic materials according $\mathrm{pH}$ drift method.

could transfer from the external surface to the internal micropores of the zeolite ${ }^{38}$. At a lower initial concentration $\left(C_{0}=1 \mathrm{mg} / \mathrm{L}\right)$ of ammonia, ammonium ions could first exchange with cations $\left(\mathrm{H}_{3} \mathrm{O}^{+}\right)$on the external surface of the zeolite and only after that it would exchange in the internal surface of the zeolite. For that reason, it is important to determine the particle size and specific surface area of the zeolites, which are related to the sorption process of ammonium (Zeo waste $3(62 \%)>$ Zeo waste $1(52 \%)$ ). The best removal efficiency was determined for Zeo waste $2(72 \%)$ because this zeolitic waste was activated with $\mathrm{H}_{2} \mathrm{O}_{2}$ and improved the zeolite sorption capacity.

The $\mathrm{pH}$ of an aqueous solution is an important controlling parameter in sorption processes and water quality parameters for a fish recirculation system. The removal of $\mathrm{NH}_{4}{ }^{+}$ions from an aqueous solution using zeolitic waste was studied at $\mathrm{pH}$ 5.5-7.0. The $\mathrm{pH}$ decreased in all solutions during all sorption durations because zeolitic waste is highly selective for $\mathrm{H}_{3} \mathrm{O}^{+}$ions when the $\mathrm{H}_{3} \mathrm{O}^{+}$ion concentration is higher. Thus, at lower $\mathrm{pH}$ values, $\mathrm{H}_{3} \mathrm{O}^{+}$ions compete with $\mathrm{NH}_{4}{ }^{+}$ions for the exchange sites in zeolitic waste samples ${ }^{39}$.

According to the $\mathrm{pH}_{\mathrm{pzc}}$ values, it is possible to evaluate the possible attraction and repulsion between zeolitic materials and ammonium in solution. Three types of zeolitic materials were analyzed by evaluating the point of zero charge $\left(\mathrm{pH}_{\mathrm{pzc}}\right)$, which was closely related to the sorption properties of the materials. Figure 7 shows the $\mathrm{pH}$ drift tests, and all curves have similar shapes. The determined $\mathrm{pH}_{\mathrm{pzc}}$ values are $5.4 \pm 0.1,5.5 \pm 0.1$ and $5.0 \pm 0.1$ for Zeo waste 1, Zeo waste 2 and Zeo waste 3, respectively (Fig. 7). The surfaces of all three samples were positive at a $\mathrm{pH}$ lower than the $\mathrm{pH}_{\mathrm{PZC}}$ and negative at a $\mathrm{pH}$ higher than the $\mathrm{pH}_{\mathrm{pzc}}$.

When the water solution has a high $\mathrm{pH}$, the amount of $\mathrm{NH}_{4}^{+}$in solution is very small, and it changes to $\mathrm{NH}_{3}$ because the dissociation constant ( $\mathrm{pKa}$ ) of $\mathrm{NH}_{4}{ }^{+}$is $9.24^{40}$. Murayama et al. ${ }^{40}$ stated that the recommended $\mathrm{pH}$ is from 4 to 10 for removal of $\mathrm{NH}_{4}{ }^{+}$in water solution by using zeolites. According to these experimental results, the $\mathrm{pH}$ was in the range of 5.5-7.0. The influence of $\mathrm{pH}$ values on removal efficiency was not observed to be significant $^{41}$. Therefore, all three types of zeolitic materials have good possibilities for ammonium ion immobilization.

Based on the above results, it can be concluded that synthetic zeolitic waste with two different granulometric compositions and one by using chemical modification with $\mathrm{H}_{2} \mathrm{O}_{2}$ are suitable adsorbents for $\mathrm{NH}_{4}{ }^{+}$ion removal and have great potential for removing ammonium ions from water, which can be used in closed fish-farming systems.

FT-IR analysis of zeolitic waste before and after ammonium ion sorption. After ammonium sorption by zeolitic waste, changes occur in the mineral composition of the zeolitic waste, which was evaluated by using FT-IR analysis. Figure 8 presents the IR spectra of the three types of zeolitic waste before and after ammonium adsorption experiments. Two initial solution concentrations of $1 \mathrm{mg} / \mathrm{L} \mathrm{NH}_{4}{ }^{+}$and $10 \mathrm{mg} / \mathrm{L} \mathrm{NH}_{4}{ }^{+}$were used. All three types of zeolitic waste before sorption have similar characteristics. The IR spectrum of zeolitic waste samples showed broad absorption bands at $3441-3466 \mathrm{~cm}^{-1}$ and $1634-1643 \mathrm{~cm}^{-1}$ attributed to the $\mathrm{OH}$ stretching vibration and usual $\mathrm{H}-\mathrm{O}-\mathrm{H}$ bending vibration, respectively ${ }^{42}$. The broad absorption bands at approximately $1083-1103 \mathrm{~cm}^{-1}$ were attributed to the asymmetrical stretching vibration of $\mathrm{Si}-\mathrm{O}-\mathrm{Si}$ and $\mathrm{Si}-\mathrm{O}-\mathrm{Al}$ in a tetrahedral. Absorption bands at $820 \mathrm{~cm}^{-1}-835 \mathrm{~cm}^{-1}$ were assigned to $\mathrm{Si}-\mathrm{O}-\mathrm{Si}$ symmetrical stretching. The peaks at $455 \mathrm{~cm}^{-1}-465 \mathrm{~cm}^{-1}$ were assigned to tetrahedral vibration. The weak peaks at $525 \mathrm{~cm}^{-1}-559 \mathrm{~cm}^{-1}$ were related to a double ring external linkage related to an FAU structure. Sang et al. ${ }^{43}$ also reported that all of the abovementioned absorption bands were typical for zeolite Y. These FT-IR peaks agreed well with the XRD patterns (Fig. 1).

It was obvious that the sorption process does not change the main mineral composition of zeolitic waste, but one new band is observed after $\mathrm{NH}_{4}{ }^{+}$sorption. In these cases, the initial solution concentration was $10 \mathrm{mg} / \mathrm{L}$ $\mathrm{NH}_{4}{ }^{+}$. Changes occurred during the sorption process and were related to the additional absorption frequencies of ammonium. The results confirmed that the main changes were observed at approximately $1389-1384 \mathrm{~cm}^{-1}$, attributing to the absorption band of $\mathrm{NH}_{4}{ }^{+}$present in the zeolite structure ${ }^{44}$. The normal modes of vibration of a free $\mathrm{NH}_{4}^{+}$ion have frequencies of $1389-1384 \mathrm{~cm}^{-1}$. When using a lower initial solution concentration of $1 \mathrm{mg} / \mathrm{L}$ $\mathrm{NH}_{4}^{+}$, the bands related to $\mathrm{NH}^{4+}$ ion frequencies were weaker compared with that of zeolitic waste materials with a higher initial solution concentration $\left(10 \mathrm{mg} / \mathrm{L} \mathrm{NH}_{4}{ }^{+}\right)$(Fig. 7).

In conclusion, it is evident that the most efficient zeolitic waste for ammonium ion sorption is Zeo waste 2. The investigated zeolitic waste materials could be an excellent material to remove ammonium impurities from water and wastewater. 

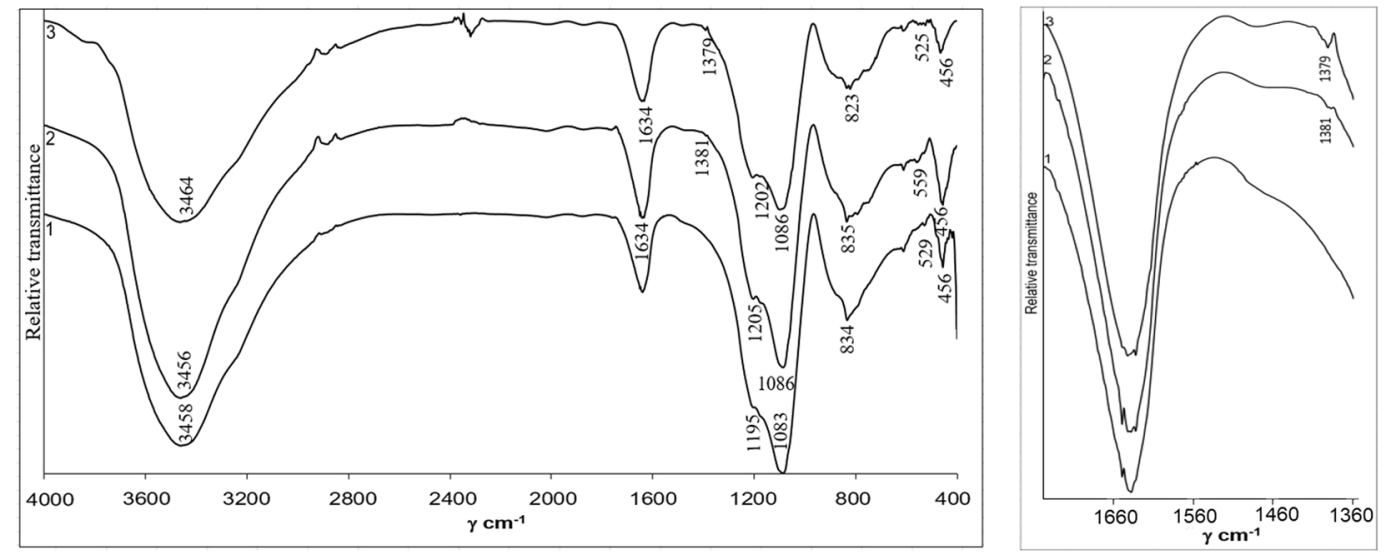

\section{Zeo waste 1}
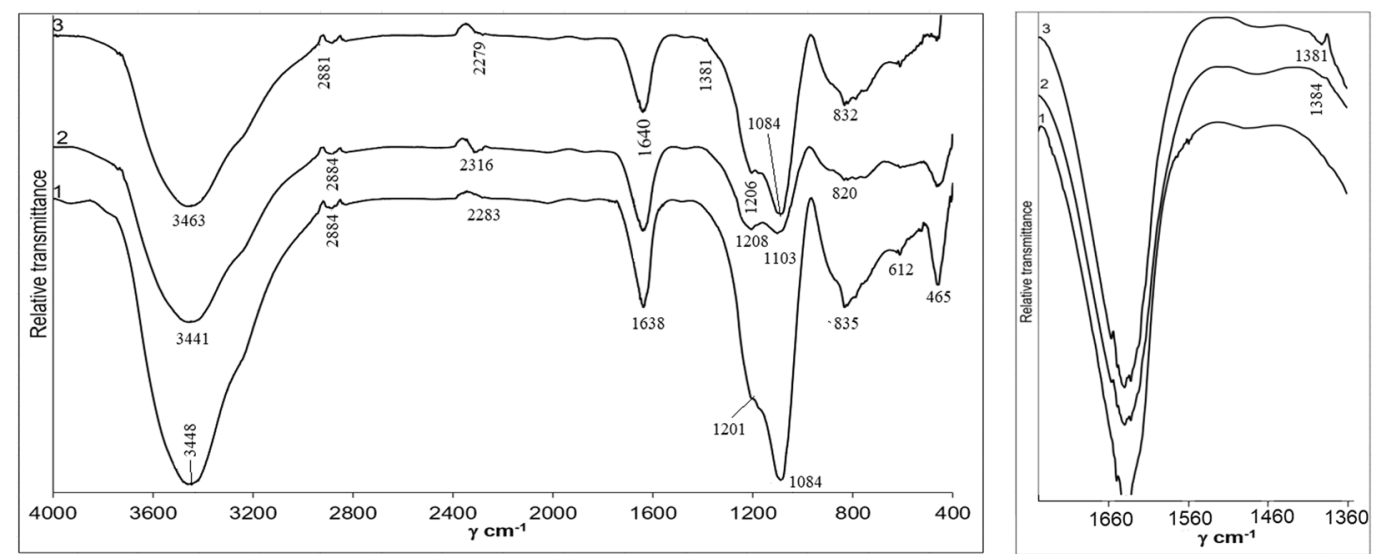

Zeo waste 2
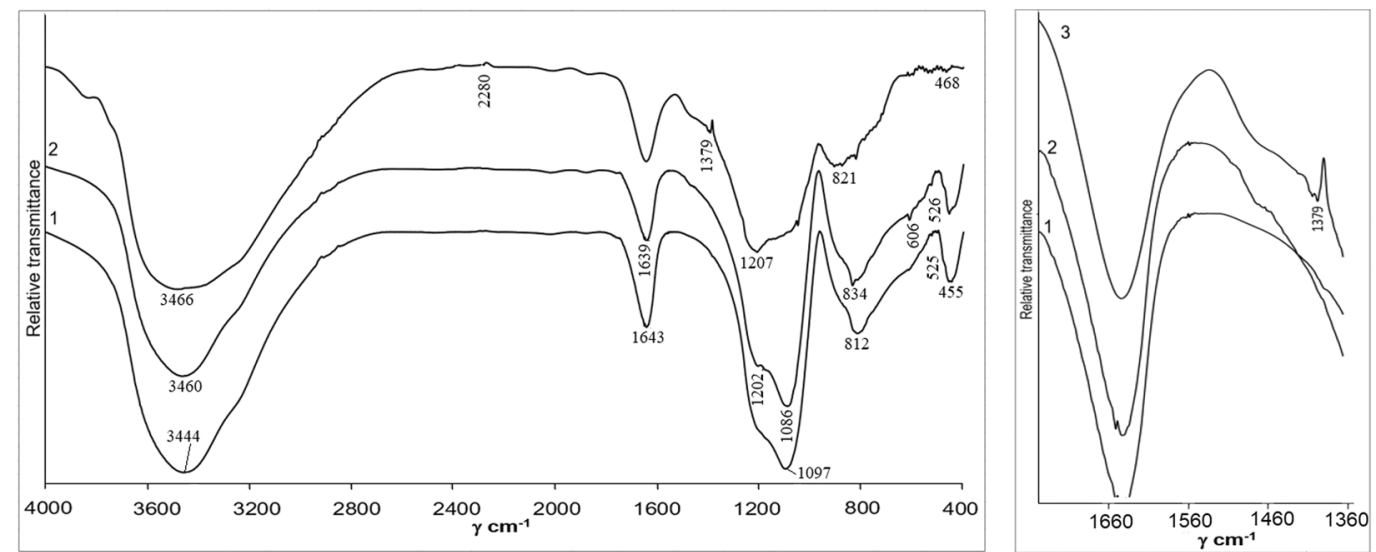

Zeo waste 3

Figure 8. IR spectra of zeolitic waste before ammonium adsorption (1) and after ammonium adsorption (2 and 3). The initial concentration of solutions was $1 \mathrm{mg} \mathrm{NH}_{4}^{+} / \mathrm{L}$ and $10 \mathrm{mg} \mathrm{NH}_{4}^{+} / \mathrm{L}$ respectively.

\section{Conclusion}

- After $\mathrm{H}_{2} \mathrm{O}_{2}$ modification of zeolitic waste (Zeo waste 2), the amount of carbon (technically, coke) significantly decreased from $3.31 \%$ in unmodified zeolitic waste to $1.25 \%$ in $\mathrm{H}_{2} \mathrm{O}_{2}$-treated zeolitic waste. Sulfur was not detected at all for the oxidation reaction. This modification did not change the mineral composition of zeolitic waste. According to XRD analysis, the zeolitic waste is composed of zeolite Y.

- All three types of zeolitic waste powders were spherical particles. According to an analysis of nitrogen adsorption-desorption isotherms, zeolitic waste demonstrated a low specific surface area SBET (approximately $\left.138 \mathrm{~m}^{2} / \mathrm{g}\right)$ and combined micropores $(0.852 \mathrm{~nm})$ and mesopores $(4.84 \mathrm{~nm})$. All three types of zeolitic waste can be classified as microporous materials with mesopores present in them. Based on the results of the 
study, the pHpzc values of Zeo waste 1, Zeo waste 2 and Zeo waste 3 were $5.4 \pm 0.1,5.5 \pm 0.1$ and 5.0 \pm 0.1 , respectively.

- The maximal ammonium ion removal efficiency of $72 \%$ was for Zeo waste 2 (zeolitic waste modified with $\mathrm{H}_{2} \mathrm{O}_{2}$ ) when the initial $\mathrm{NH}_{4}{ }^{+}$ion concentration was $1 \mathrm{mg} / \mathrm{L}$. This could be related to the highest pore surface area of $143.70 \mathrm{~m}^{2} / \mathrm{g}$ compared with those of the other two types of investigated zeolitic waste. When the initial $\mathrm{NH}_{4}{ }^{+}$ion concentration was higher $(10 \mathrm{mg} / \mathrm{L})$, equilibrium times were reached after $15 \mathrm{~min}$, and the removal efficiency was approximately $23 \%$ for all three types of zeolitic waste.

- In this study, experimental results showed that zeolitic waste materials are suitable adsorbents for the removal of $\mathrm{NH}_{4}{ }^{+}$ion impurities from water and wastewater. In our experimental conditions, the maximum removal efficiency was $72 \%$ for $\mathrm{NH}_{4}{ }^{+}$ions.

Received: 4 June 2019; Accepted: 4 December 2019;

Published online: 15 January 2020

\section{References}

1. Cui, X., Hao, H., Zhang, C., He, Z. \& Yang, X. Capacity and mechanisms of ammonium and cadmium sorption on different wetlandplant derived biochars. Sci. Total Environ. 539, 566-575, https://doi.org/10.1016/j.scitotenv.2015.09.022 (2016).

2. Karri, R. R., Sahu, J. N. \& Chimmiri, V. Critical review of abatement of ammonia from wastewater. J. Molec. Liq. 261, 21-31, https:// doi.org/10.1016/j.molliq.2018.03.120 (2018).

3. Ramesh, K. \& Reddy, D. D. Zeolites and their potential uses in agriculture. Adv. agron. 113, 219-241, https://doi.org/10.1016/B9780-12-386473-4.00004-X (2011).

4. Yang, H. I. et al. Adsorption of ammonium in aqueous solutions by pine sawdust and wheat straw biochars. Envir. Sc. Pollut. Res. 25, 25638-25647, https://doi.org/10.1007/s11356-017-8551-2 (2018).

5. Tian, W. et al. Remediation of aquaculture water in the estuarine wetlands using coal cinder-zeolite balls/reed wetland combination strategy. J. Envir. Manag. 181, 261-268, https://doi.org/10.1016/j.jenvman.2016.06.040 (2016).

6. Yin, H., Yang, C., Jia, Y., Chen, H. \& Gu, X. Dual removal of phosphate and ammonium from high concentrations of aquaculture wastewaters using an efficient two-stage infiltration system. Sc. Total Envir. 635, 936-946, https://doi.org/10.1016/j. scitotenv.2018.04.218 (2018).

7. Sánchez-Hernández, R., Padilla, I., López-Andrés, S. \& López-Delgado, A. Al-Waste-Based Zeolite Adsorbent Used for the Removal of Ammonium from Aqueous Solutions. Internat. J. Chem. Engineer. 1256197; https://doi.org/10.1155/2018/1256197 (2018).

8. Huo, H. et al. Ammonia-nitrogen and phosphates sorption from simulated reclaimed waters by modified clinoptilolite. J. Hazard. Mater. 229, 292-297, https://doi.org/10.1016/j.jhazmat.2012.06.001 (2012).

9. Xue, R. et al. Simultaneous removal of ammonia and N-nitrosamine precursors from high ammonia water by zeolite and powdered activated carbon. J. Environ. Sc. 64, 82-91, https://doi.org/10.1016/j.jes.2017.02.010 (2018).

10. Metropoulos, K., Maliou, E., Loizidou, M. \& Spyrellis, N. Comparative studies between synthetic and natural zeolites for ammonium uptake. J. Environm. Sc. \& Health, Part A 28, 1507-1518, https://doi.org/10.1080/10934529309375958 (1993).

11. Wang, Y. F., Lin, F. \& Pang, W. Q. Ammonium exchange in aqueous solution using Chinese natural clinoptilolite and modified zeolite. J. Hazard. Mater. 142, 160-164, https://doi.org/10.1016/j.jhazmat.2006.07.074 (2007).

12. Markou, G., Vandamme, D. \& Muylaert, K. Using natural zeolite for ammonia sorption from wastewater and as nitrogen releaser for the cultivation of Arthrospira platensis. Biores. Technol. 155, 373-378, https://doi.org/10.1016/j.biortech.2013.12.122 (2014).

13. Crippen, M. \& Khrisnan, J. S. The combination of adsorption with modified zeolite and aquaphonic system to remove total ammonia nitrogen in fish pond. Working Paper http://repository.wima.ac.id/id/eprint/4356 (2016).

14. Wu, K. et al. Evaluation of the adsorption of ammonium-nitrogen and phosphate on a granular composite adsorbent derived from zeolite. Envir. Sc. Pollut. Res. 26, 17632-17643, https://doi.org/10.1007/s11356-019-05069-2 (2019).

15. Bergero, D. et al. Ammonia removal capacity of European natural zeolite tuffs: application to aquaculture waste water. Aquacult. Res. 25, 813-821, https://doi.org/10.1111/j.1365-2109.1994.tb00745.x (1994).

16. Gonzalez, M. R., Pereyra, A. M., Sánchez, R. M. T. \& Basaldella, E. I. Chromium removal by zeolite-rich materials obtained from an exhausted FCC catalyst: Influence of chromium incorporation on the sorbent structure. J. Colloid Interface Sci. 408, 21-24, https:// doi.org/10.1016/j.jcis.2013.06.055 (2013).

17. Sun, D., Li, X. Z., Brungs, M. \& Trimm, D. Encapsulation of heavy metals on spent fluid catalytic cracking catalyst. Water Sci. Technol. 38, 211-217, https://doi.org/10.1016/S0273-1223(98)00530-7 (1998).

18. Nizevičienè, D., Vaičiukynienė, D., Vaitkevičius, V. \& Rudžionis, Ž. Effects of waste fluid catalytic cracking on the properties of semihydrate phosphogypsum. J. Clean. Product. 137, 150-156, https://doi.org/10.1016/j.jclepro.2016.07.037 (2016).

19. Bruker. D8 Advance diffractometer (Bruker AXS) technical details. Preprint at https://www.bruker.com/products/x-ray-diffractionand-elemental-analysis/X-ray-diffraction/d8-advance.html (2019).

20. Bruker. X-ray S8 Tiger WD Series 2 technical details. Preprint at https://www.bruker.com/products/X-ray-diffraction-andelemental-analysis/x-ray-fluorescence/s8-tiger.html (2019).

21. CILAS. 1090 Particle Size Analyzer. Preprint at https://www.pharmaceuticalonline.com/doc/cilas-1090-particle-size-analyzer-0002 (2019).

22. Zeiss. EVO MA and LS Series Scanning Electron Microscopes for Materials Analysis and Life Science. Operator User Guide. Version 1.0. (Cambridge 2008).

23. PerkinElmer. Frontier FT-IR, NIR and FIR Spectroscopy Brochure. Preprint at https://www.perkinelmer.com/lab-solutions/ resources/docs/BRO_FrontierFTIR.pdf (2019).

24. Quantachrome Instruments. Characterizing Porous Materials and Powders Autosorb iQ and ASiQwin Gas Sorption System. Operating Manual. Version 2.0. P/N 05098-2.0 Rev B. (Boynton Beach, 2009-2011).

25. Kümmel, R. \& Worch, E. Adsorption aus wäßrigen Lösungen, https://doi.org/10.1002/zfch.19900301225 (Leipzig, 1990).

26. Nasiruddin Khan, M. \& Sarwar, A. Determination of points of zero charge of natural and treated adsorbents. Surface Rev. Lett. 14, 461-469, https://doi.org/10.1142/S0218625X07009517 (2007).

27. Rezvani, M., Najafpour, G., Mohammadi, M. \& Zare, H. Amperometric biosensor for detection of triglyceride tributyrin based on zero point charge of activated carbon. Turkish J. Biolog. 41, 268-277, https://doi.org/10.3906/biy-1607-24 (2017).

28. Canli, M., Abali, Y. \& Bayca, S. U. Removal of methylene blue by natural and Ca and K-exchanged zeolite treated with hydrogen peroxide. Physicochem. Probl. Miner. Process. 49, 481-496, https://yadda.icm.edu.pl/baztech/element/bwmetal.element.baztech09c41802-4144-4aae-acf9-1b0f24fec41f/c/Canli.pdf (2013).

29. Singh S. Regenerating spent zeolites with $\mathrm{UV}$ and $\mathrm{UV} / \mathrm{H}_{2} \mathrm{O}_{2}$ to enhance removal of endocrine disrupting compounds. Environm. Water Resourc. Engin. Masters Projects 1-95, https://doi.org/10.7275/G96G-2773 (2010). 
30. Koryabkina, N., Bergendahl, J. A., Thompson, R. W. \& Giaya, A. Adsorption of disinfection by products on hydrophobic zeolites with regeneration by advanced oxidation. Micropor. Mesopor. Mater. 104, 77-82, https://doi.org/10.1016/j.micromeso.2007.01.060 (2007).

31. Wang, W. P., Wang, W. \& Zhou, Y. Q. Adsorption characteristics of natural zeolite on ammonia nitrogen. Advanc. Mater. Res. 599, 501-504, https://doi.org/10.4028/www.scientific.net/AMR.599.501 (2012).

32. Wen, D., Ho, Y. S. \& Tang, X. Comparative sorption kinetic studies of ammonium onto zeolite. J. hazardous mater. 133, 252-256, https://doi.org/10.1016/j.jhazmat.2005.10.020 (2006).

33. Rodríguez, E. D. et al. Geopolymers based on spent catalyst residue from a fluid catalytic cracking (FCC) process. Fuel 109, 493-502, https://doi.org/10.1016/j.fuel.2013.02.053 (2013).

34. Sing, K. S. W. et al. Reporting physisorption data for gas/solid systems with special reference to the determination of surface area and porosity. Pure Appl. Chem. 57, 603-619, https://doi.org/10.1351/pac198557040603 (1985).

35. Brunauer, S., Emmett, P. H. \& Teller, E. Adsorption of Gases in Multimolecular Layers. J. Am. Chem. Soc. 60, 309-319 (1938).

36. Lin, L. et al. Adsorption mechanisms of high levels of ammonium onto natural and NaCl-modified zeolites. Separ. Purif. Technol. 103, 15-20, https://doi.org/10.1016/j.seppur.2012.10.005 (2013).

37. Franus, M., Wdowin, M., Bandura, L. \& Franus, W. Removal of environmental pollutions using zeolites from fly ash: A review. Fresenius Environ. Bull. 24, 854-866 (2015).

38. Kotoulas, A. et al. Zeolite as a potential medium for ammonium recovery and second cheese whey treatment. Water 11, 1-23, https://doi.org/10.3390/w11010136 (2019).

39. Ji, Z., Yuan, J. \& Li, X. Removal of ammonium from wastewater using calcium form clinoptilolite. J. Hazard. Mater. 141, 483-488, https://doi.org/10.1016/j.jhazmat.2006.07.010 (2007).

40. Murayama, N., Yoshida, S., Takami, Y., Yamamoto, H. \& Shibata, J. Simultaneous removal of $\mathrm{NH}_{4}{ }^{+}$and $\mathrm{PO}_{4}{ }^{3-}$ in aqueous solution and its mechanism by using zeolite synthesized from coal fly ash. Separat. Sc. Technol. 38, 113-130, https://doi.org/10.1081/SS120016701 (2003).

41. Saltalı, K., Sarı, A. \& Aydın, M. Removal of ammonium ion from aqueous solution by natural Turkish (Yıldizeli) zeolite for environmental quality. J. hazardous mater. 141, 258-263, https://doi.org/10.1016/j.jhazmat.2006.06.124 (2007).

42. Rege, S. U. \& Yang, R. T. A novel FTIR method for studying mixed gas adsorption at low concentrations: $\mathrm{H}_{2} \mathrm{O}$ and $\mathrm{CO}_{2}$ on $\mathrm{NaX}$ zeolite and $\gamma$-alumina. Chem. engineer. sc. 56, 3781-3796, https://doi.org/10.1016/S0009-2509(01)00095-1 (2001).

43. Sang, S. et al. Synthesis of small crystals zeolite NaY. Mater. Lett. 60, 1131-1133, https://doi.org/10.1016/j.matlet.2005.10.110 (2006).

44. Madhurambal, G., Mojumdar, S., Hariharan, S. \& Ramasamy, P. TG, DTA, FTIR and Raman spectral analysis of $\mathrm{Zn}_{\mathrm{a}} / \mathrm{Mg}_{\mathrm{b}}$ ammonium sulfate mixed crystals. J. thermal analysis and calorimetry 78, 125-133, https://doi.org/10.1023/B:JTAN.0000042160.82063.c4 (2004).

\section{Author contributions}

We all authors: D. Vaičiukynienè, A. Mikelionienè, A. Baltušnikas, A. Kantautas and A. Radzevičius declare that we contributed to this article in equal parts about $20 \%$ everybody: D. Vaičiukyniene and A. Kantautas analyzed the results of chemical composition of zeolitic waste which was determined by XRF. According XRD the mineral composition of zeolitic waste was evaluated by D. Vaičiukynienė and A. Kantautas. Mikelionienè and A. Baltušnikas done the analysis of particles size distribution. Mikelionienè and A. Radzevičius carry out the modification of zeolitic waste. Kantautas and A. Radzevičius done analysis of the microstructures of three type's zeolitic waste investigations. The data of FT-IR spectrometry were analysed by D. Vaičiukynienė and A. Baltušnikas, The textural parameters of the zeolitic waste (nitrogen adsorption-desorption isotherms) were evaluated by D. Vaičiukynienè, A. Baltušnikas and A. Kantautas The evaluation of the $\mathrm{NH}_{4}^{+}$concentration was evaluated according Nessler method done by A. Mikelionienè and A. Radzevičius.

\section{Competing interests}

The authors declare no competing interests.

\section{Additional information}

Correspondence and requests for materials should be addressed to D.V.

Reprints and permissions information is available at www.nature.com/reprints.

Publisher's note Springer Nature remains neutral with regard to jurisdictional claims in published maps and institutional affiliations.

(c) (1) Open Access This article is licensed under a Creative Commons Attribution 4.0 International License, which permits use, sharing, adaptation, distribution and reproduction in any medium or format, as long as you give appropriate credit to the original author(s) and the source, provide a link to the Creative Commons license, and indicate if changes were made. The images or other third party material in this article are included in the article's Creative Commons license, unless indicated otherwise in a credit line to the material. If material is not included in the article's Creative Commons license and your intended use is not permitted by statutory regulation or exceeds the permitted use, you will need to obtain permission directly from the copyright holder. To view a copy of this license, visit http://creativecommons.org/licenses/by/4.0/.

(C) The Author(s) 2020 